\title{
Nitratireductor indicus sp. nov., isolated from deep-sea water
}

Correspondence

Zongze Shao

shaozz@163.com

\author{
Qiliang Lai, Zhiwei Yu, Jun Yuan, Fengqin Sun and Zongze Shao
}

Key Laboratory of Marine Biogenetic Resources, Third Institute of Oceanography, State Oceanic Administration, Xiamen, People's Republic of China

\begin{abstract}
A taxonomic study was carried out on a novel bacterial strain, designated $\mathrm{C} 115^{\top}$, isolated from a crude-oil-degrading consortium, enriched from deep-sea water of the Indian Ocean. Cells were Gram-negative short rods, mobile by means of a monopolar flagellum. Growth was observed at salinities of $0-7 \%$ and at $10-43{ }^{\circ} \mathrm{C}$. It was unable to degrade Tween 80 or gelatin. $16 \mathrm{~S}$ rRNA gene sequence analysis showed that strain $\mathrm{C}_{11} 5^{\mathrm{T}}$ was related most closely to Nitratireductor aquibiodomus $\mathrm{NL}^{2} 1^{\top}$ (96.5\% similarity), Nitratireductor kimnyeongensis $\mathrm{KY} 101^{\top}$ (96.4\%) and Nitratireductor basaltis $\mathrm{J}^{\top}(96.2 \%)$. The predominant fatty acids were summed feature 8 $\left(\mathrm{C}_{18: 1} \omega 7 c\right.$ and/or $\left.\mathrm{C}_{18: 1} \omega 6 c, 81.8 \%\right)$ and $\mathrm{C}_{18: 0}(7.0 \%)$. The $\mathrm{G}+\mathrm{C}$ content of the chromosomal DNA of strain $\mathrm{C} 115^{\top}$ was $59 \mathrm{~mol} \%$. Based on its morphology, physiology and fatty acid composition together with 16S rRNA gene sequence comparisons, the novel strain most appropriately belongs to the genus Nitratireductor, but can be distinguished readily from recognized species of the genus. Strain $\mathrm{C}_{11} 15^{\top}$ is therefore considered to represent a novel species of the genus Nitratireductor, for which the name Nitratireductor indicus sp. nov. is

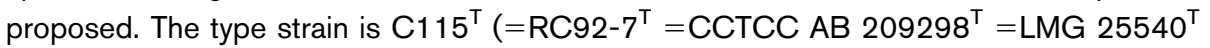
$=\operatorname{MCCC} 1 \mathrm{~A}^{2} 1260^{\top}$ ).
\end{abstract}

The genus Nitratireductor, belonging to the family Phyllobacteriaceae, was proposed by Labbé et al. (2004) and, at the time of writing, comprises three recognized species, Nitratireductor aquibiodomus (Labbé et al., 2004), Nitratireductor kimnyeongensis (Kang et al., 2009) and Nitratireductor basaltis (Kim et al., 2009). In this study, we isolated a novel strain, designated $\mathrm{C} 115^{\mathrm{T}}$, from a crude-oildegrading consortium enriched from a deep-sea water sample collected from the Indian Ocean. The strain was found to be related phylogenetically to members of the genus Nitratireductor. Characterization and classification of strain $\mathrm{C} 115^{\mathrm{T}}$ were based on data from the present polyphasic study.

Deep-sea water was sampled with Niskin bottles attached to a CTD (conductivity, temperature and depth) sampler in December 2005 during cruise DY-105A of R/V Da-Yang $\mathrm{Yi}$-Hao. The sampling site was located at $25.3217^{\circ} \mathrm{S}$ $70.0405^{\circ} \mathrm{E}$ in the south-western part of the Indian Ridge, at a water depth of $2488 \mathrm{~m}$. The seawater was enriched with crude oil, and bacteria in the community were isolated on marine agar 216L according to Lai et al. (2009). Strain $\mathrm{C} 115^{\mathrm{T}}$ was obtained as a novel bacterium. It was further

\footnotetext{
The GenBank/EMBL/DDBJ accession number for the $16 \mathrm{~S}$ rRNA gene sequence of strain $\mathrm{C} 115^{\top}$ is GU447302.

A supplementary figure and a supplementary table are available with the online version of this paper.
}

cultivated for morphological and biochemical characterization on marine agar 2216 (BD).

Genomic DNA was prepared according to the method of Ausubel et al. (1995) and the 16S rRNA gene was amplified by PCR by using the primers described previously (Liu \& Shao, 2005). Sequences of related taxa were obtained from the GenBank database. Phylogenetic analysis was performed by using MEGA version 4 (Tamura et al., 2007) after multiple alignment of the data by DNAMAN (version 5.1; Lynnon Biosoft). Distances (distance options according to Kimura's two-parameter model) and clustering with the neighbour-joining method of Saitou \& Nei (1987) and minimum-evolution method of Rzhetsky \& Nei (1992, 1993) were determined by using bootstrap values based on 1000 replications.

A nearly full-length $16 \mathrm{~S}$ rRNA gene sequence (1448 nt) of strain $\mathrm{C} 115^{\mathrm{T}}$ was obtained. Phylogenetic analysis of strain $\mathrm{C} 115^{\mathrm{T}}$ indicated that it belonged to the family Phyllobacteriaceae, forming a robust clade with members of the genus Nitratireductor in the neighbour-joining tree (Fig. 1); a similar tree topology was obtained with the minimum-evolution method. Strain $\mathrm{C} 115^{\mathrm{T}}$ was related most closely to N. aquibiodomus $\mathrm{NL}^{\mathrm{T}}{ }^{\mathrm{T}}$ (96.5\% 16S rRNA gene sequence similarity), $N$. kimnyeongensis $\mathrm{KY} 101^{\mathrm{T}}$ $(96.4 \%)$ and $N$. basaltis $\mathrm{J}^{\mathrm{T}}(96.2 \%)$. Levels of $16 \mathrm{~S}$ rRNA gene sequence divergence between strain $\mathrm{C} 115^{\mathrm{T}}$ and the type strains of recognized Nitratireductor species were 


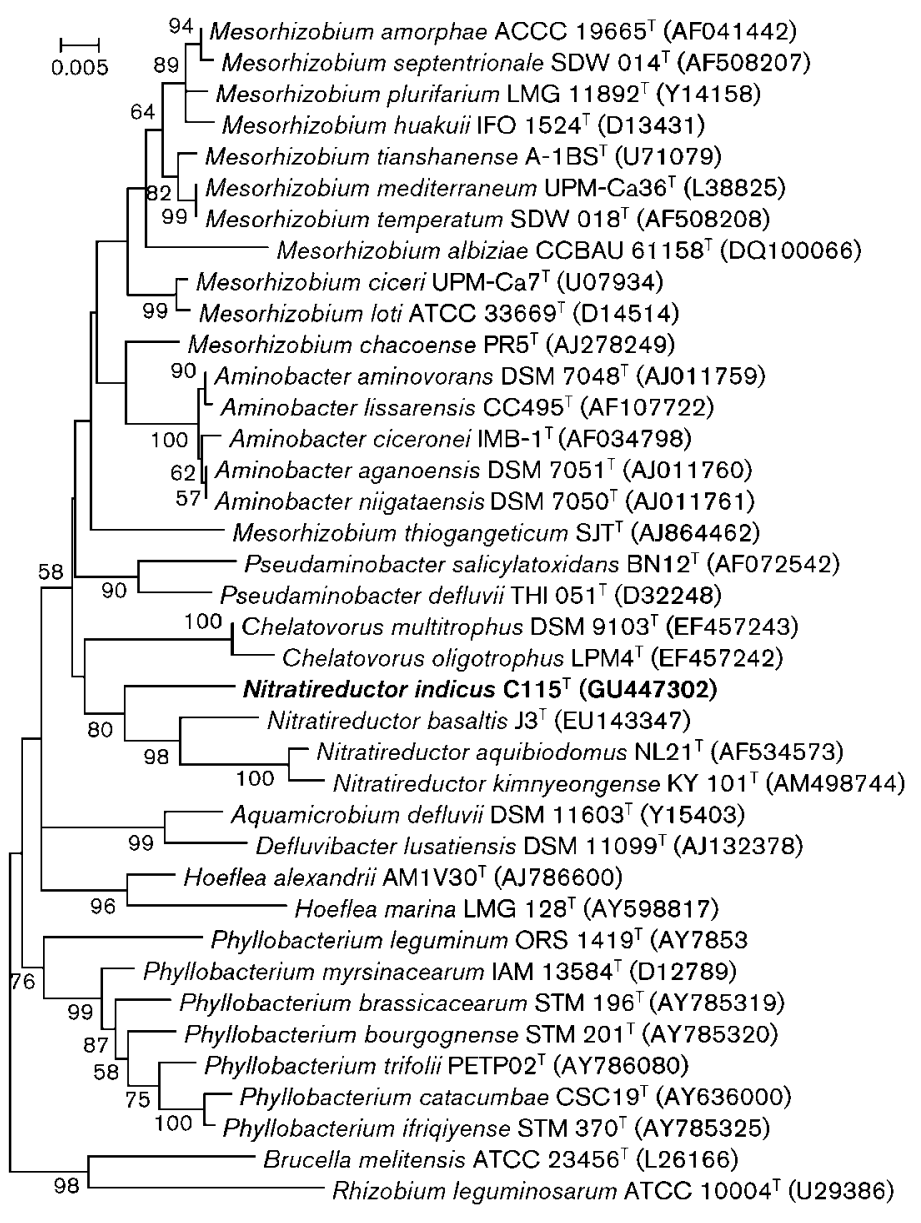

Fig. 1. Neighbour-joining tree showing the phylogenetic positions of strain $\mathrm{C} 115^{\top}$ and representatives of some other related taxa, based on 16S rRNA gene sequences. Bootstrap values (expressed as percentages of 1000 replications) are shown at branch points. Bar, 0.005 nucleotide substitution rate $\left(K_{\text {nuc }}\right)$ units. $\geqslant 3.5 \%$, and thus the data support the view that strain $\mathrm{C} 115^{\mathrm{T}}$ represents a novel species.

Gram staining, catalase, oxidase and lipase (Tween 80) activities, hydrolysis of aesculin and starch, optimal growth temperature and $\mathrm{pH}$, tolerance of $\mathrm{NaCl}$ and general cell morphology were studied as described previously (Lai et al., 2009). Other biochemical tests were carried out by using API 20NE and API ZYM strips (bioMérieux) and Biolog GN2 microplates according to the manufacturers' instructions, except that the $\mathrm{NaCl}$ concentration was adjusted in all tests to $3.0 \%$. N. aquibiodomus DSM $15645^{\mathrm{T}}, N$. kimnyeongensis KCTC $22759^{\mathrm{T}}$ and $N$. basaltis KCTC $22119^{\mathrm{T}}$ were tested at the same time for comparison. The results of these tests are given in the species description and in Table 1.

The $\mathrm{G}+\mathrm{C}$ content of the chromosomal DNA was determined according to the methods described by Mesbah \& Whitman (1989) by using reversed-phase HPLC. The DNA G+C content of strain $\mathrm{C} 115^{\mathrm{T}}$ was $59 \mathrm{~mol} \%$, a value close to those given for the type strains of the three recognized Nitratireductor species (56.7$60.4 \mathrm{~mol} \%$ ).

Fatty acids in whole cells grown on marine agar 2216 at $28{ }^{\circ} \mathrm{C}$ for $48 \mathrm{~h}$ were extracted, saponified and esterified, followed by GC analysis of the fatty acid methyl esters according to the instructions of the MIDI system (Sasser, 1990). The fatty acid profiles of $N$. aquibiodomus DSM $15645^{\mathrm{T}}, N$. kimnyeongensis KCTC $22759^{\mathrm{T}}$ and N. basaltis KCTC $22119^{\mathrm{T}}$ were determined in parallel with that for strain $\mathrm{C} 115^{\mathrm{T}}$ in this study. The detailed results are shown in Supplementary Table S1, available in IJSEM Online. The major fatty acids of strain $\mathrm{C} 115^{\mathrm{T}}$ were summed feature $8\left(\mathrm{C}_{18: 1} \omega 7 c\right.$ and/or $\left.\mathrm{C}_{18: 1} \omega 6 c ; 81.8 \%\right)$ and $\mathrm{C}_{18: 0}$ $(7.0 \%)$, similar to the data for $N$. basaltis KCTC $22119^{\mathrm{T}}$. Strain $C 115^{\mathrm{T}}$ could be differentiated from the type strains of $N$. aquibiodomus and $N$. kimnyeongensis based on the proportion of summed feature 8 and $\mathrm{C}_{19: 0}$ cyclo $\omega 8 c$ ( $>15 \%$ difference). The proportions of the individual fatty acids of the three reference type strains were slightly different from those given in the original publications.

Antibiotic susceptibility tests were performed by the disc diffusion method according to Lai et al. (2009); antibiotic discs were obtained from Oxoid. Strain $\mathrm{C} 115^{\mathrm{T}}$ and the type strains of $N$. aquibiodomus, $N$. kimnyeongensis and $N$. basaltis were tested at the same time in this study. All four strains were sensitive to ( $\mu$ g per disc) cefalexin (30), cefobid (30), chloromycetin (30), erythromycin (15), rifampicin (5) and rocephin (30), but resistant to 
Table 1. Differential characteristics between strain $\mathrm{C} 115^{\top}$ and the type strains of recognized Nitratireductor species

Strains: 1 , C115 ${ }^{\mathrm{T}} ; 2$, N. aquibiodomus $\mathrm{NL} 21^{\mathrm{T}}$ (unless indicated, data from Labbé et al., 2004); 3, N. kimnyeongensis $\mathrm{KY} 101^{\mathrm{T}}$ (Kang et al., 2009); 4, N. basaltis $\mathrm{J}^{\mathrm{T}}$ (Kim et al., 2009). In API 20NE tests in our study, all strains were negative for indole production, D-glucose fermentation and gelatin hydrolysis. In API ZYM tests in our study, all strains were positive for acid phosphatase, alkaline phosphatase, esterase (C4), leucine aminopeptidase, trypsin and valine aminopeptidase and negative for $\alpha$-fucosidase, $\alpha$-mannosidase, $\beta$-glucosidase and $\beta$-glucuronidase. + , Positive; w, weakly positive; -, negative. ND, No data available.

\begin{tabular}{|c|c|c|c|c|}
\hline Characteristic & 1 & 2 & 3 & 4 \\
\hline Isolation source & Deep-sea water & Denitrification system & Seaweed & Black sand \\
\hline Cell shape & Rods & Rods & Rods & Coccoids, rods \\
\hline Motility & + & + & + & - \\
\hline \multicolumn{5}{|l|}{$\mathrm{NaCl}$ concentration for growth $(\%, \mathrm{w} / \mathrm{v})$} \\
\hline Range & $0-7$ & $0-5$ & $0-7$ & $0-8$ \\
\hline \multicolumn{5}{|l|}{ Temperature for growth $\left({ }^{\circ} \mathrm{C}\right)$} \\
\hline Range & $10-37$ & $\mathrm{ND}$ & $10-45$ & $15-45$ \\
\hline Optimum & $25-30$ & $30-35$ & 30 & $\mathrm{ND}$ \\
\hline \multicolumn{5}{|l|}{ API $20 \mathrm{NE}$ results ${ }^{\star}$} \\
\hline Arginine dihydrolase & + & $\mathrm{W}$ & $\mathrm{W}$ & - \\
\hline Urease & + & $\mathrm{w}$ & $\mathrm{W}$ & - \\
\hline D-Mannitol & - & $\mathrm{W}$ & $\mathrm{W}$ & + \\
\hline Potassium gluconate & - & $\mathrm{w}$ & - & + \\
\hline Adipic acid & + & - & - & + \\
\hline D-Glucose, $N$-acetylglucosamine & + & + & $\mathrm{w}$ & + \\
\hline D-Mannose & + & + & + & - \\
\hline Malic acid, phenylacetic acid & + & - & - & - \\
\hline Trisodium citrate & + & + & - & - \\
\hline \multicolumn{5}{|l|}{ API ZYM results* } \\
\hline Esterase lipase (C8) & - & + & + & + \\
\hline$N$-Acetyl- $\beta$-glucosaminidase & - & + & - & - \\
\hline$\alpha$-Galactosidase, $\beta$-galactosidase & - & - & - & + \\
\hline Cephradin, streptomycin, tetracycline, vibramycin & - & + & + & + \\
\hline Ampicillin, carbenicillin, piperacillin & + & - & - & + \\
\hline Cefazolin, penicillin $\mathrm{G}$ & + & - & + & + \\
\hline DNA G $+\mathrm{C}$ content $(\mathrm{mol} \%)$ & 59 & 57 & 60.4 & 56.7 \\
\hline
\end{tabular}

${ }^{\star}$ Data from this study using the strains listed in the text.

kanamycin (30), lincomycin (2) and metronidazole (5). Detailed results of antibiotic susceptibility tests are given in Table 1.

On the basis of morphological, physiological and chemotaxonomic characteristics, together with data from $16 \mathrm{~S}$ rRNA gene sequence comparisons, strain $\mathrm{C}_{115^{\mathrm{T}}}$ is considered to represent a novel species of the genus
Nitratireductor, for which the name Nitratireductor indicus sp. nov. is proposed.

\section{Description of Nitratireductor indicus sp. nov.}

Nitratireductor indicus (in'di.cus. L. masc. adj. indicus Indian, referring to the Indian Ocean, from where the type strain was isolated). 
Cells are rods, about $3.0 \mu \mathrm{m}$ long and $1.3 \mu \mathrm{m}$ wide, mobile by means of at least one polar flagellum (Supplementary Fig. S1). Positive for catalase, oxidase, urease, arginine dihydrolase, $\beta$-galactosidase, $\beta$-glucosidase (aesculin hydrolysis) and nitrate reduction, but negative for the Gram reaction, indole production, D-glucose fermentation, lipase (Tween 80), amylase, gelatinase and denitrification. After 3 days of incubation at $28{ }^{\circ} \mathrm{C}$ on marine agar, produces smooth grey colonies with regular edges that are $2-3 \mathrm{~mm}$ in diameter, non-pigmented and slightly raised in the centre. Grows in the presence of $0-7 \% \mathrm{NaCl}$ (optimum $3 \%$ ) and at $10-43{ }^{\circ} \mathrm{C}$ (optimum $25-30{ }^{\circ} \mathrm{C}$ ); no growth is observed at $45{ }^{\circ} \mathrm{C}$ after 1 week. The major fatty acids are $\mathrm{C}_{18: 0}$ and summed feature $8\left(\mathrm{C}_{18: 1} \omega 7 c / \omega 6 c\right)$. Sensitive to ( $\mu \mathrm{g}$ per disc, unless otherwise indicated) ampicillin (10), carbenicillin (100), cefalexin (30), cefazolin (30), cefobid (30), chloromycetin (30), erythromycin (15), penicillin G (10), piperacillin (100), rifampicin (5), rocephin (30) and vibramycin (30), but resistant to cephradin (30), ciprofloxacin (5), clindamycin (2), co-trimoxazole (25), gentamicin (10), kanamycin (30), lincomycin (2), metronidazole (5), minomycin (30), norfloxacin (10), ofloxacin (5), oxacillin (1), polymyxin B (30 IU), streptomycin (10), tetracycline (30) and vancomycin (30). In the API ZYM system, positive for acid phosphatase, alkaline phosphatase, cystine aminopeptidase, esterase (C4), leucine aminopeptidase, lipase (C14), naphthol-AS-BI-phosphoamidase, trypsin, valine aminopeptidase, $\alpha$-chymotrypsin and $\alpha$ glucosidase, but negative for esterase lipase (C8), $N$-acetyl$\beta$-glucosaminidase, $\alpha$-fucosidase, $\alpha$-galactosidase, $\alpha$-mannosidase, $\beta$-galactosidase, $\beta$-glucosidase and $\beta$-glucuronidase. In the API 20NE system, utilizes adipic acid, Dglucose, D-mannose, malic acid, $\mathrm{N}$-acetylglucosamine, phenylacetic acid and trisodium citrate, but not capric acid, maltose, D-mannitol, L-arabinose or potassium gluconate. Of the 95 substrates in the Biolog GN2 system, positive for acetic acid, cis-aconitic acid, citric acid, DLlactic acid, D-alanine, D-mannose, trehalose, glycerol, glycyl L-glutamic acid, hydroxy-L-proline, L-alanine, L-alanyl glycine, L-asparagine, L-aspartic acid, L-glutamic acid, Lhistidine, L-leucine, L-ornithine, L-proline, L-pyroglutamic acid, L-threonine, malonic acid, methyl pyruvate, myoinositol, monomethyl succinate, $\mathrm{N}$-acetyl-D-glucosamine, propionic acid, succinamic acid, sucrose, turanose, urocanic acid, $\alpha$-D-glucose, $\alpha$-hydroxybutyric acid, $\alpha$-ketobutyric acid, $\alpha$-ketoglutaric acid, $\alpha$-ketovaleric acid, $\beta$ hydroxybutyric acid and $\gamma$-aminobutyric acid, weakly positive for DL- $\alpha$-glycerol phosphate, glycogen, glycyl Laspartic acid, maltose, succinic acid, Tween 80 and $\gamma$ hydroxybutyric acid; negative for the remainder. The DNA $\mathrm{G}+\mathrm{C}$ content of the type strain is $59 \mathrm{~mol} \%$. Table 1 shows the characteristics used to distinguish the type strain from those of related species.

The type strain, $\mathrm{C} 115^{\mathrm{T}}\left(=\mathrm{RC} 92-7^{\mathrm{T}}=\mathrm{CCTCC}\right.$ AB $209298^{\mathrm{T}}$ $=\mathrm{LMG} 25540^{\mathrm{T}}=$ MCCC $\left.1 \mathrm{~A} 01260^{\mathrm{T}}\right)$, was isolated from deep-sea water of the Indian Ocean.

\section{Acknowledgements}

This work was supported financially by the Scientific Research Foundation of Third Institute of Oceanography, SOA (no. 2009065), the COMRA program (no. DYXM115-02-2-05) and the National Infrastructure of Natural Resources for Science and Technology Program of China (no. 2005DKA21209).

\section{References}

Ausubel, F. M., Brent, R., Kingston, R. E., Moore, D. D., Seidman, J. G., Smith, J. A. \& Struhl, K. (editors) (1995). Short Protocols in Molecular Biology: a Compendium of Methods from Current Protocols in Molecular Biology, 3rd edn. New York: Wiley.

Kang, H. S., Yang, H. L. \& Lee, S. D. (2009). Nitratireductor kimnyeongensis sp. nov., isolated from seaweed. Int J Syst Evol Microbiol 59, 1036-1039.

Kim, K.-H., Roh, S. W., Chang, H.-W., Nam, Y.-D., Yoon, J.-H., Jeon, C. O., Oh, H.-M. \& Bae, J.-W. (2009). Nitratireductor basaltis sp. nov., isolated from black beach sand. Int J Syst Evol Microbiol 59, 135-138.

Labbé, N., Parent, S. \& Villemur, R. (2004). Nitratireductor aquibiodomus gen. nov., sp. nov., a novel $\alpha$-proteobacterium from the marine denitrification system of the Montreal Biodome (Canada). Int J Syst Evol Microbiol 54, 269-273.

Lai, Q., Yuan, J., Gu, L. \& Shao, Z. (2009). Marispirillum indicum gen. nov., sp. nov., isolated from a deep-sea environment. Int J Syst Evol Microbiol 59, 1278-1281.

Liu, C. \& Shao, Z. (2005). Alcanivorax dieselolei sp. nov., a novel alkane-degrading bacterium isolated from sea water and deep-sea sediment. Int J Syst Evol Microbiol 55, 1181-1186.

Mesbah, M. \& Whitman, W. B. (1989). Measurement of deoxyguanosine/thymidine ratios in complex mixtures by high-performance liquid chromatography for determination of the mole percentage guanine + cytosine of DNA. J Chromatogr 479, 297-306.

Rzhetsky, A. \& Nei, M. (1992). A simple method for estimating and testing minimum-evolution trees. Mol Biol Evol 9, 945-967.

Rzhetsky, A. \& Nei, M. (1993). Theoretical foundation of the minimum-evolution method of phylogenetic inference. Mol Biol Evol 10, 1073-1095.

Saitou, N. \& Nei, M. (1987). The neighbor-joining method: a new method for reconstructing phylogenetic trees. Mol Biol Evol 4, 406425.

Sasser, M. (1990). Identification of bacteria by gas chromatography of cellular fatty acids, MIDI Technical Note 101. Newark, DE: MIDI.

Tamura, K., Dudley, J., Nei, M. \& Kumar, S. (2007). MEGA4: molecular evolutionary genetics analysis (MEGA) software version 4.0. Mol Biol Evol 24, 1596-1599. 